
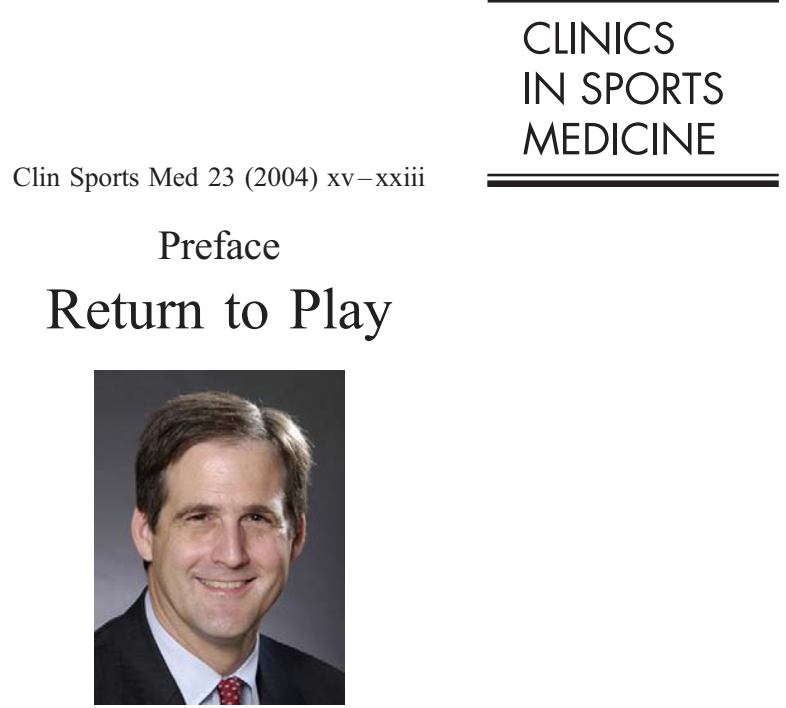

Edward G. McFarland, MD

Guest Editor

The topic for this issue of the Clinics in Sports Medicine was conceived after a seminar presented at the Advanced Team Physician Course (ATPC) in 2002. The ATPC is a course designed for sports medicine physicians that covers topics in more detail and covers more controversial topics than many sports meetings. It is cosponsored by the American College of Sports Medicine, the American Medical Society for Sports Medicine, and the American Orthopaedic Society for Sports Medicine. Many of the contributors to this issue were participants in that symposium, and they were chosen to contribute here because of their expertise and experience with these issues. All of them are team physicians in some capacity or deal with athletes who are referred to their practices.

The topic of return to play has always been pertinent for anyone who treats athletes or active individuals. Returning a patient to an active life is not only a core concept of sports medicine but has implications for health care professionals from almost every discipline. Margo Putukian, MD, suggested that the issue of return to play has an impact on patients of any age from 5 to 85 and can apply to "almost any medical condition" [1]. When do you let the 5-year-old with a forearm bone fracture return to gymnastics, a college athlete with manicdepressive illness return to stressful competition, and the octogenarian with a hernia repair return to long-distance running? As practitioners, particularly as sports medicine physicians, we are faced with making these decisions and making recommendations to patients on a daily basis.

There are four facets of the discussion regarding decisions to return a participant to play. The first is the medical component, and it is the one that is perhaps the least well defined of all. Although we all prefer certainty in this life, complete 
knowledge about most conditions we see in patients is rarely available. The practice of medicine is an inexact science, and this is a truism that is not always appreciated by the athlete or the other people in their lives. To make more specific recommendations, we should know the pathophysiology and natural history of the disease process, the result of both medical and surgical interventions, and when those interventions will allow the individual to return to play without further injury to themselves or to other participants. There are few conditions for which there are not gaps in our knowledge of these factors. As we begin to understand the complexity of many conditions, the decision-making often seems to become more difficult because there are many more factors to consider. This usually is a good thing, because we serve our patients better by attempting to understand all of the medical variables when evaluating return to play issues. For example, there is probably not a more controversial topic than when to return an athlete to play after a cerebral concussion, but the process of trying to develop cognitive tests for sideline use have taught us a lot about the variable presentations and recovery of athletes who sustain this injury. However, this has also generated further questions such as, "What measures are the most predictive of a safe ability to return to play and are predictive of no further injury?" As most medical practitioners are aware, there is so much biologic variability that it is difficult to say that guidelines to return to play will protect every individual, whether one is talking about concussions, myocardial infarctions, or stress fractures. Medical knowledge evolves, as does our understanding of most disease processes; our recommendations about return to play will change as well. When making decisions to return to play, one must try to obtain the best medical knowledge possible, make judgments about the individual patient, and hope for the best.

The second variable to consider in decisions for return to play involve social and economic forces. Although sports medicine physicians are well aware of these influences, I am amazed how often these factors influence decision-making for returning patients to physical education classes or to their health club. The social influences when deciding return to play include the patient's family, their parents, their friends, the coaching staff and sometimes other medical practitioners. The pressure for an athlete to return for "the big game" that can be applied by these other parties can be overt or they may be more occult. They sometimes seem to make our lives as practitioners miserable, but they are an important part of understanding our patients, their goals, and their recovery from a condition or injury. Pressures should be dealt with when making decisions about diagnostic tests, treatment options, surgery, rehabilitation, or return to play.

An ancillary social consideration is the economic impact of decisions to return to play, and this can occur at any level of participation. The impact of return to play upon income and endorsement benefits for professionals or Olympic-level athletes is easy to understand, but there are also economic implications of injury for collegiate athletes who are on scholarship and high school students who may be pursuing a scholarship. Unfortunately, economic benefits can be perceived by amateur athletes and their families who hope to attain fame and fortune through athletic participation. Although it is tempting to disregard unrealistic goals of 
economic gain when making decisions to return to play, these forces should be recognized and dealt with when counseling patients and their families.

Another factor involved when making the decision to return to play is political; that is, who politically is in the position to make the decision regarding whether or not a patient returns to activity or to participation? As outlined in the consensus statement in the Appendix, there should be a system established by the physicians, trainers, and institutions to determine who makes the decision and when [2]. Disagreements between health care providers, second-opinion physicians, trainers, and therapists can create unnecessary stress. The process of making the decision regarding return to play should consider the best interest of the athlete as the primary goal, and the decision to play should not be left up to the coach or the administrator. This process should include having a chain of command, a method of communicating the decisions to the appropriate personel, a method of documentation, and a system for protecting the privacy of the player.

The final facet of return to play decisions involves legal issues. Legislation sometimes dictates how health care professionals should deal with certain injuries, and these rules can be federal, statewide, local, or specific to the school. For example, there are several regulations regarding an athlete's participation in sport while taking certain medications, and the practitioner should not provide narcotics or other medications to players simply so they can play. In a larger legal sense, the physician has an obligation to put the best interest of the patient first; this relates to return to play issues, but also to eligibility decisions [3]. A physician should not allow a player to return to play when it is not believed to be medically safe, despite the desire of or pressure by the player, agent, family, or coach. Likewise, a player should not be allowed to sign a waiver when the player is not really ready to participate.

It is important to recognize that the topics discussed by the authors of this issue of the Clinics of Sports Medicine are controversial. Our medical knowledge of these conditions continues to change, and this will influence how the conditions are evaluated and treated. As a result, the recommendations by the authors regarding return to play should be recognized as guidelines. The recommendations made by these authors should not be interpreted as legal standards for return to play for any of the topics presented herein. Decisions to return to play must continue to be individualized and must include recognition of the highly variable natural history of most medical conditions and the complex interaction of social, economic, political, and legal factors.

\section{Appendix. The team physician and return-to-play issues: a consensus statement}

\section{Definition}

Return-to-play is the process of deciding when an injured or ill athlete may safely return to practice or competition. 


\section{Goal}

The goal is to return an injured or ill athlete to practice or competition without putting the individual or others at undue risk for injury or illness.

To accomplish this goal, the team physician should have knowledge and be involved with:

- Establishing a return-to-play process

- Evaluating injured or ill athletes

- Treating injured or ill athletes

- Rehabilitating injured or ill athletes

- Returning an injured or ill athlete to play

\section{Summary}

The objective of this consensus statment is to provide physicians who are responsible for the health care of teams with a decision process for determining when to return an injured or ill athlete to practice or competition. This statement is not intended as a standard of care, and should not be interpreted as such. This statement is only a guide, and as such is of a general nature consistent with the reasonable and objective practice of the health care professional. Individual decisions regarding the return of an injured or ill athlete to play will depend on the specific facts and circumstances presented to the physician.

Adequate insurance should be in place to help protect the athlete, the sponsoring organization, and the physician.

This statement was developed by the collaborative effort of six major professional associations concerned with clinical sports medicine issues; they have committed to forming an ongoing project-based alliance to "bring together sports medicine organizations to best serve active people and athletes." The organizations are: the American Academy of Family Physicians, the American Academy of Orthopaedic Surgeons, the American College of Sports Medicine, the American Medical Society for Sports Medicine, the American Orthopaedic Society for Sports Medicine, and the American Osteopathic Academy of Sports Medicine.

\section{Expert panel}

Stanley A. Herring, MD, Chair, Seattle, Washington

John A. Bergfeld, MD, Cleveland, Ohio

Joel Boyd, MD, Edina, Minnesota

Timothy Duffey, DO, Columbus, Ohio

Karl B. Fields, MD, Greensboro, North Carolina

William A. Grana, MD, Tucson, Arizona

Peter Indelicato, MD, Gainesville, Florida

W. Ben Kibler, MD, Lexington, Kentucky

Robert Pallay, MD, Hillsborough, New Jersey 
Margot Putukian, MD, University Park, Pennsylvania

Robert E. Sallis, MD, Alta Loma, California

Establishing a return-to-play process

Establishing a process for returning an athlete to play is an essential first step in deciding when an injured or ill athlete may safely return to practice or competition.

It is essential for the team physician to coordinate:

- Establishing a chain of command regarding decisions to return an injured or ill athlete to practice or competition

- Communicating the return-to-play process to players, families, certified athletic trainers, coaches, administrators, and other health care providers

- Establishing a system for documentation

- Establishing protocols to release information regarding an athlete's ability to return to practice or competition after an injury or illness

It is essential that the return-to-play process address the:

- Safety of the athlete

- Potential risk to the safety of other participants

- Functional capabilities of the athlete

- Functional requirements of the athlete's sport

- Federal, state, local, school, and governing body regulations related to returning an injured or ill athlete to practice or competition

\section{Evaluating injured or ill athletes}

Evaluation of an injured or ill athlete establishes a diagnosis, directs treatment, and is the basis for deciding when an athlete may safely return to practice or competition. Repeated evaluations throughout the continuum of injury or illness management optimize medical care.

It is essential that evaluation of an injured or ill athlete include:

- A condition-specific medical history

- A condition-specific physical examination

- Appropriate medical tests and consultations

- Psychosocial assessment

- Documentation

- Communication with the player, family, certified athletic trainer, coaches, and other health care providers

In addition, it is desirable that:

- The team physician coordinate evaluation of the injured or ill athlete 


\section{Treating injured or ill athletes}

Treatment of an injured or ill athlete promotes the safe and timely return to practice or competition.

It is essential that treatment of the injured or ill athlete:

- Begin in a timely manner (see Sideline Preparedness for the Team Physician: A Consensus Statement, 2000)

- Follow an individualized plan, which may include consultations and referrals

- Include a rehabilitation plan

- Include equipment modification, bracing, and orthoses as necessary

- Address psychosocial issues

- Provide a realistic prognosis as to a safe and timely return to practice or competition

- Include continued communication with the player, family, certified athletic trainer, coaches, and other health care providers

- Include documentation

In addition, it is desirable that:

- The team physician coordinate the initial and ongoing treatment for the injured or ill athlete

\section{Rehabilitating injured or ill athletes}

Comprehensive treatment includes proper rehabilitation of an injured or ill athlete, thus optimizing the safe and timely return to practice or competition. The team physician should be involved in a network that integrates expertise regarding rehabilitation. This network should include certified athletic trainers, physical therapists, medical specialists, and other health care providers.

It is essential that the rehabilitation network:

- Coordinate the development of a rehabilitation plan that is designed to:

- Restore function of the injured part

- Restore and promote musculoskeletal and cardiovascular function, as well as overall well-being of the injured or ill athlete

- Provide sport-specific assessment and training to serve as a basis for sportspecific conditioning (see The Team Physician and Conditioning of Athletes for Sports: A Consensus Statement, 2001)

- Provide for continued equipment modification, bracing, and orthoses

- Continue communication with the player, family, rehabilitation network, and coaches concerning the athlete's progress

- Include documentation 
In addition, it is desirable that:

- The team physician coordinate the rehabilitation program for the injured or ill athlete

Returning an injured or ill athlete to play

The decision for safe and timely return of an injured or ill athlete to practice or competition is the desired result of the process of evaluation, treatment, and rehabilitation.

It is essential for return-to-play that the team physician confirm the following criteria:

- The status of anatomical and functional healing

- The status of recovery from acute illness and associated sequelae

- The status of chronic injury or illness

- That the athlete pose no undue risk to the safety of other participants

- Restoration of sport-specific skills

- Psychosocial readiness

- Ability to perform safely with equipment modification, bracing, and orthoses

- Compliance with applicable federal, state, local, school, and governing body regulations

Before return-to-play, these criteria should be confirmed at a satisfactory level.

\section{Conclusion}

Use of the information in this document allows the team physician to make an informed decision as to whether an injured or ill athlete may safely return to practice or competition.

The return-to-play process should be under the direction of the team physican whenever possible. While it is desirable that the team physician coordinate evaluating, treating, and rehabilitating the injured or ill athlete, it is essential that the the team physician ultimately be responsible for the return-toplay decision.

Individual decisions regarding return of an injured or ill athlete to play will depend on the specific facts and circumstances presented to the team physician.

\section{Available resources}

Ongoing education pertinent to the team physician is essential. Information regarding team physician-specific educational opportunities can be obtained from the six participating organizations: 
- American Academy of Family Physicians (AAFP), 11400 Tomahawk Creek Pkwy, Leawood, KS 66211. 800-274-2237. www.aafp.org.

- American Academy of Orthopaedic Surgeons (AAOS), 6300 N. River Rd., Rosemont, IL 60018. 800-346-AAOS. www.aaos.org.

- American College of Sports Medicine (ACSM), 401 W. Michigan St., Indianapolis, IN 46202. 317-637-9200. www.acsm.org.

- American Medical Society for Sports Medicine (AMSSM), 11639 Earnshaw, Overland Park, KS 66210. 913-327-1415. www.amssm.org.

- American Orthopaedic Society for Sports Medicine (AOSSM), 6300 N. River Rd., Suite 200, Rosemont, IL 60018. 847-292-4900. www. sportsmed.org.

- American Osteopathic Academy of Sports Medicine (AOASM), 7611 Elmwood Ave., Suite 201, Middleton, WI. 53562. 608-831-4400. www. aoasm.org.

From The team physician and return to play issues: a consensus statement. Med Sci Sports Exerc 2002;34:1212-4; with permisssion.

\section{References}

[1] Putukian M. Return to play: making the tough decisions. Phys Sportsmed 1998;26:25-7.

[2] The team physician and return to play issues: a consensus statement. Med Sci Sports Exerc 2002; $34: 1212-4$.

[3] Mitten MJ. When is disqualification from sports justified? Medical judgment vs patients' rights. Phys Sportsmed 1996;24:75-8.

\section{Further readings}

26th Bethesda Conference: recommendations for determining eligibility for competition in athletes with cardiovascular abnormalities. January 6-7, 1994. Med Sci Sports Exerc 1994;26:S223-83.

AAFP, AAP, AMSSM, AOSSM, AOASM. Preparticipation physical evaluation. In: The physician and sportsmedicine. 2nd edition. Minneapolis (MN): McGraw-Hill Healthcare; 1997.

Adams BB. Transmission of cutaneous infections in athletes. Br J Sports Med 2000;34:413-4.

American Academy of Pediatrics Committeee on Sports Medicine and Fitness. Cardiac dysrhythmias and sports. Pediatrics 1995;95:786-8.

Cantu RC. Stingers, transient quadriplegia and cervical spinal stenosis; return-to-play criteria. Med Sci Sports Exerc 1997;29:S233-5.

Goodman RA, Thacker SB, Solomon SL, Osterholm MT, Hughes JM. Infectious disease in competitive sports. JAMA 1994;271:862-7.

Herring SA. Rehabilitation of muscle injuries. Med Sci Sports Exerc 1990;22:453-6.

Kibler WB, Herring SA, Press JM. Functional rehabilitation of sports and muskuloskeletal injuries. Gaithersburg (MD): Aspen; 1998. 
Kibler WB, Livingston BP. Closed-chain rehabilitation for upper and lower extremities. J Am Acad Orthop Surg 2001;9:412-21.

Maron BJ. Cardiovascular risks to young persons on the athletic field. Ann Intern Med 1998; 129:379-86.

Mellion MB, Walsh WM, Madden C, Putukian M, Shelton GL, editors. Team physician's handbook. 3rd edition. Philadelphia: Hanley \& Beltus; 2002.

Mitten MJ, Mitten RJ. Legal considerations in treating the injured ahtlete. J Orhtop Sports Phys Ther $1995 ; 21: 38-43$.

The American Medical Society for Sports Medicine (AMSSM) and the American Academy of Sports Medicine (AASM). Human immunodeficiency virus and other blood-borne pathogens in sports. Clin J Sport Med 1995;5:199-204.

Edward G. McFarland, MD

Division of Sports Medicine and Shoulder Surgery Department of Orthopaedic Surgery

The Johns Hopkins University

10753 Falls Road, Suite 215

Lutherville, MD 21093, USA

E-mail address: emcfarl@jhmi.edu 